\title{
Radiologists and rheumatologists on performing and reporting shoulder ultrasound: from disagreement to consensus
}

\author{
G. Filippou', A. Adinolfi', A. Delle Sedie'2, E. Filippucci ${ }^{3}$, A. lagnocco ${ }^{4}$, F. Porta ${ }^{5}$, \\ L.M. Sconfienza ${ }^{6}$, S. Tormenta ${ }^{7}$, V. Di Sabatino ${ }^{1}$, V. Picerno ${ }^{1}$, B. Frediani ${ }^{1}$ \\ ${ }^{1}$ Rheumatology Unit, University of Siena, Siena; ${ }^{2}$ Rheumatology Unit, University of Pisa, Pisa; \\ ${ }^{3}$ Clinic of Rheumatology, Polytechnic University of Marche, Jesi (AN); \\ ${ }^{4}$ Rheumatology Department, La Sapienza University, Rome; ${ }^{5}$ Rheumatology Unit, University of Florence, \\ Florence; ${ }^{6}$ Unit of Radiology, San Donato Hospital, San Donato Milanese (MI); \\ ${ }^{7}$ Department of Diagnostic Imaging, S. Pietro Fatebenefratelli Hospital, Rome, Italy
}

\begin{abstract}
SUMMARY
Shoulder pain is a common condition in the rheumatologist's practice, yet there are no guidelines on how to report shoulder ultrasound (US) examinations. The aim of this study was to compare scanning and reporting techniques performed by radiologists and rheumatologists and identify any discrepancies between the two.

The participants in this study were five rheumatologists and two radiologists specialized in musculoskeletal US. The study was divided in 2 phases. In the first phase, each participant performed an US of 3 patients and reported the findings without knowing the patient diagnosis and the findings reported by the other operators. Other three investigators reported the US technique of each operator. Reports and images were subsequently compared to identify any discrepancies and reach consensus on a common approach. In the second phase, a US scan was performed on a fourth patient in a plenary session to assess feasibility and efficacy of the common approach

The US scanning technique was similar for all operators. The differences in reporting emerged in the description of the rotator cuff disease. Radiologists provided a detailed description of lesions (measurements along 2 axis and scoring of lesions), whereas rheumatologists described carefully the inflammatory changes. The experts concluded that lesions should be measured along 2 axes and the grade of degeneration and the age of the lesion should be reported. Another difference emerged in the description of the irregularities of the bone surface. The experts concluded that the term erosion should be used only when an inflammatory joint disease is suspected.

This study led to the clarification of some inconsistencies in US reporting, and represented an interesting collaborative experience between radiologists and rheumatologists.
\end{abstract}

Key words: Ultrasound, Shoulder, Report, Scanning technique, Rotator cuff.

Reumatismo, 2014; 66 (3): 233-239

\section{INTRODUCTION}

ainful shoulder (PS) is a frequently encountered condition in the rheumatologist's daily practice (1). As shoulder pain can be the result of several conditions, a correct diagnosis is fundamental in order to establish the most appropriate treatment (2). Over the last few years, ultrasound (US) scanning has proven useful in the assessment of PS and many authors have described the correct approach to shoulder US scanning (2-6).

Over ten years ago, a group of rheumatologists specialized in musculoskeletal US (MSUS) identified and proposed for the first time the main clinical indications for US scanning of the shoulder and other joints in a rheumatologic setting (7). More recently, a group of experts of the European Society of Musculoskeletal Radiology (ESSR) addressed the main diagnostic in-
Corresponding author: Antonella Adinolfi Rheumatology Unit

Policlinico Santa Maria alle Scotte Viale Bracci, 16 - 53100 Siena, Italy E-mail: antonella.adinolfi986@gmail.com 
dications for US scanning of the shoulder and other joints using a Delphi approach based on a literature review (8).

However, although rheumatologists and musculoskeletal radiologists are interested in the same field of application of US, to the best of our knowledge, there are no shared guidelines to report shoulder US findings.

The aim of this study was to compare the technical and reporting approach to shoulder US scanning between radiologists and rheumatologists specialized in MSUS, identify the main differences and propose a final consensus-based approach.

\section{MATERIALS AND METHODS}

Seven operators, two radiologists (LMS and ST) and five rheumatologists (GF, EF, ADS, FP, AI) participated in this project. They all had at least a ten-year experience in MSUS. Four patients were enrolled and asked to sign an informed consent. The study was conducted in two stages: in the first stage, each operator performed a shoulder US scan of three patients. The patients were scanned in separate rooms using three Esaote MyLab 25XVG machines equipped with linear $7-12 \mathrm{MHz}$ probes. In an adjacent room, three reporting stations were created, where each operator could generate a detailed report of all US findings for each scanned shoulder and save the most relevant images in a hard disk.

The US scans and reports were carried out without any previous discussion among the operators and all of them were blinded to the patient diagnosis and the findings reported by the other operators. Furthermore, three other investigators (AA, VDS, VP), experts in MSUS, observed and described the US technique adopted by each operator, indicating the type and number of scans made during the US examination. At the end of the scanning and reporting session, images and reports of all the operators and the observers were compared in order to identify the main differences. Subsequently, the operators discussed the differences and tried to codify a common approach both for the US scanning technique and the reporting method.

In the second phase of the study, the common approach to shoulder US was tested. A single operator performed a shoulder US examination of a fourth patient in a plenary session (all operators were blinded to the patient medical history), while the images were projected in real time on a large screen, trying to adopt the previously selected approach. During the exam, other operators could intervene if necessary, proposing a different technique or scanning method that could be more appropriate and, in that case, all participants voted for the best solution for the issue raised. At the end of the exam, the experts reported the findings using the same common approach and then compared the reports again to ensure consensus was reached.

\section{RESULTS}

The first phase of the study lasted $7 \mathrm{~h}$ and the second $5 \mathrm{~h}$.

The operators adopted a very similar US scanning technique. The only difference was in the sequence of scans.

Table I reports the main differences in the scanning techniques between the participants in this study and the scans recommended by radiologists and rheumatologists, as described in the literature $(6,7)$.

According to the experts, a shoulder US report should consist of a descriptive part, indicating structural abnormalities, and a final part in which the conclusions from the exam are drawn. The descriptive part could be useful for other colleagues, experts in US, while the conclusions should be written clearly so that they can be easily understood by other colleagues who are not familiar with US. The conclusions could be indicated either in the descriptive part (separately for each structure) or at the end of the report for all the structures examined. All operators agreed that the main structures assessed (summarized in Table I) should be described also when normal.

The issues raised during the discussion of 
Table I - Main differences in the scanning techniques between the participants in this study and the scans recommended by radiologists and rheumatologists.

\begin{tabular}{|c|c|c|c|}
\hline $\begin{array}{l}\text { Anatomical } \\
\text { structure }\end{array}$ & $\begin{array}{l}\text { Backhaus, Annals } \\
\text { of Rheum Dis } 2001\end{array}$ & Jacobson, Radiology, 2011 & Sonographers of this study \\
\hline $\begin{array}{l}\text { Long head of the } \\
\text { biceps tendon }\end{array}$ & $\begin{array}{l}\text { Anterior longitudinal } \\
\text { and transverse } \\
\text { scans, only static }\end{array}$ & $\begin{array}{l}\text { Anterior longitudinal and transverse } \\
\text { scans, both static and dynamic } \\
\text { (scan of the tendon from the } \\
\text { proximal to the distal edge) }\end{array}$ & $\begin{array}{l}\text { Longitudinal and transverse } \\
\text { scans, both static and dynamic } \\
\text { (scan the entire tendon, sliding } \\
\text { the probe over the tendon) }\end{array}$ \\
\hline $\begin{array}{l}\text { Subscapularis } \\
\text { tendon }\end{array}$ & $\begin{array}{l}\text { Longitudinal and } \\
\text { transverse scans, } \\
\text { only static }\end{array}$ & $\begin{array}{l}\text { Longitudinal and transverse scans, } \\
\text { only static }\end{array}$ & $\begin{array}{l}\text { Longitudinal and transverse } \\
\text { scans, both static and dynamic } \\
\text { during passive external rotation } \\
\text { of the arm }\end{array}$ \\
\hline $\begin{array}{l}\text { Supraspinatus } \\
\text { tendon }\end{array}$ & $\begin{array}{l}\text { Lateral longitudinal } \\
\text { scan }\end{array}$ & $\begin{array}{l}\text { Longitudinal and transverse scans, } \\
\text { putting the patient's arm in the } \\
\text { modified Crass position (patient's } \\
\text { ipsilateral hand placed on the } \\
\text { closest hip or buttock region) }\end{array}$ & $\begin{array}{l}\text { Longitudinal and transverse } \\
\text { scans, using the modified Crass } \\
\text { position }\end{array}$ \\
\hline $\begin{array}{l}\text { Infraspinatus } \\
\text { tendon }\end{array}$ & $\begin{array}{l}\text { Posterior } \\
\text { longitudinal scan }\end{array}$ & $\begin{array}{l}\text { Posterior longitudinal and } \\
\text { transverse scans. It is often helpful } \\
\text { to place the patient's ipsilateral } \\
\text { hand on the contralateral shoulder }\end{array}$ & $\begin{array}{l}\text { Posterior longitudinal scan, both } \\
\text { static and dynamic (by extra- } \\
\text { rotating the arm) }\end{array}$ \\
\hline Glenohumeral joint & $\begin{array}{l}\text { Axillary longitudinal } \\
\text { scan with raised } \\
\text { arm } \\
\end{array}$ & Posterior longitudinal scan & $\begin{array}{l}\text { Longitudinal scans on the } \\
\text { posterior recess and in doubtful } \\
\text { cases at the axillary recess }\end{array}$ \\
\hline $\begin{array}{l}\text { Acromionclavicular } \\
\text { joint }\end{array}$ & Longitudinal scan & $\begin{array}{l}\text { Longitudinal scan both static and } \\
\text { dynamic, asking the patient to } \\
\text { move his or her ipsilateral hand to } \\
\text { the opposite shoulder }\end{array}$ & Longitudinal scan \\
\hline $\begin{array}{l}\text { Subacromial } \\
\text { impingement }\end{array}$ & No explanation & $\begin{array}{l}\text { Dynamic scan assessed through } \\
\text { abduction movements with the } \\
\text { probe placed over the supero- } \\
\text { lateral aspect of shoulder }\end{array}$ & $\begin{array}{l}\text { Dynamic scan, assessed through } \\
\text { abduction movements of the arm } \\
\text { with the probe in coronal scan } \\
\text { and by intra-and extra-rotation } \\
\text { of the arm with the probe } \\
\text { positioned over the coraco- } \\
\text { acromial ligament }\end{array}$ \\
\hline
\end{tabular}

the reports concerned the description of the following findings:

- Tendon tears: the experts concluded that both quantitative measurements (along 2 axes) and the qualitative assessment of lesions and tendon quality are important and, when possible, an evaluation of tear timing (acute, chronic) of the lesion should be indicated in the final report (Figures 1 and 2). Specific scoring systems should be provided only when explicitly requested.

- Calcific deposits within the tendons: all deposits that arise from the bony cortex and expand within the tendon should be reported as enthesophytes, while calcific deposits, located within the tendon, but not in contact with the cortex should be defined as calcifications.

- Humeral head: the experts believed that

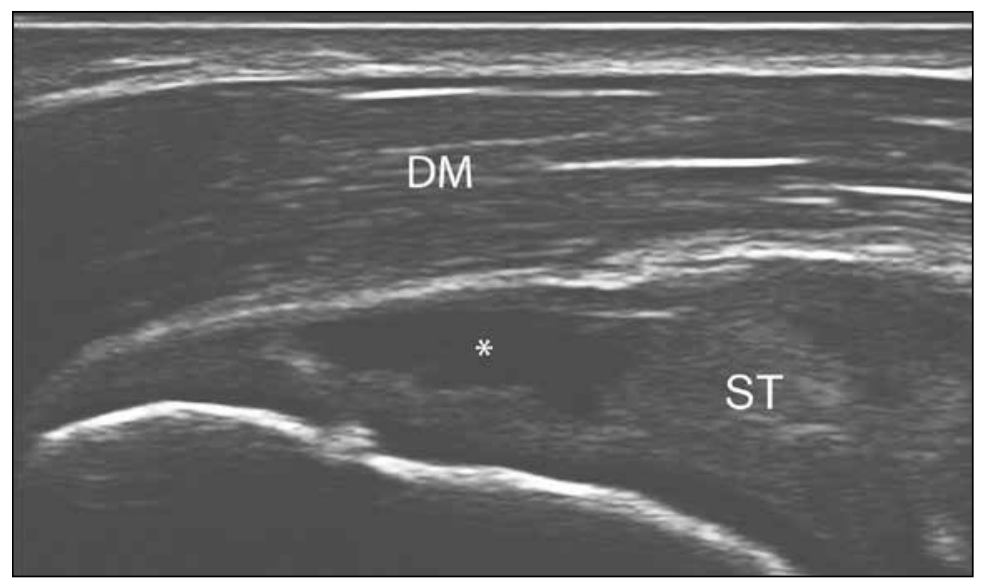

Figure 1 - Partial thickness tear of the supraspinatus tendon: longitudinal view showing an anechoic area of the bursal surface of the tendon (asterisk) in its pre-insertional tract due to the interruption of the tendon fibers for a partial thickness tear (The tears should be measured along two axes). DM, deltoid muscle; ST, supraspinatus tendon. 
abnormalities of the bony cortex of the humeral head should be described as irregularities. The term erosion should be exclusively reserved for patients with chronic (inflammatory) arthritis.

- Inflammation: the experts agreed that the creation of a descriptive score would be very useful in order to improve the description of the inflammatory changes (such as

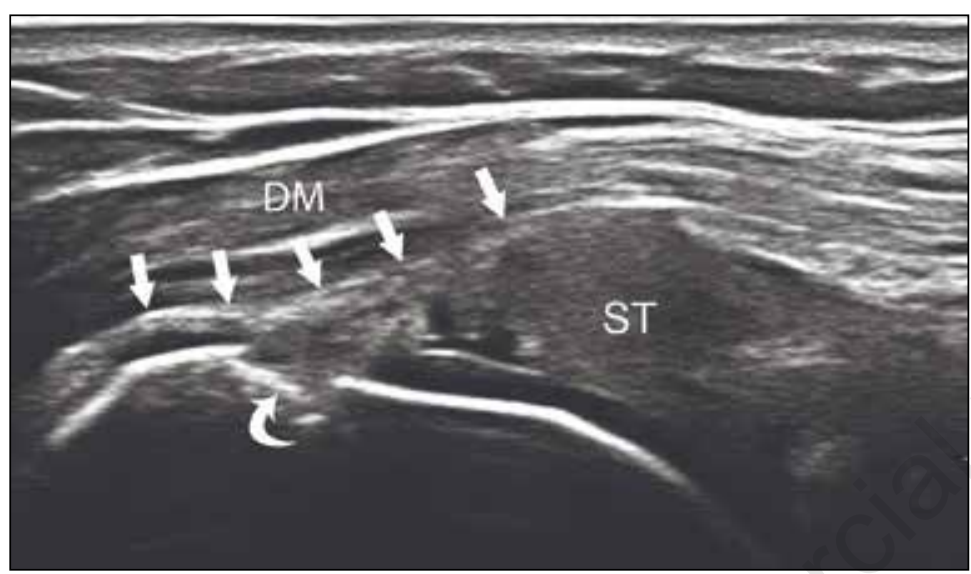

Figure 2 - Full-thickness lesion of the supraspinatus tendon. Longitudinal scan on the supraspinatus tendon showing bursal surface depression of the insertional tract of the tendon with loss of all fibers (arrows) (The tears should be measured along two axes). Some irregularities of the humeral head are also present (curved arrows). DM, deltoid muscle; ST, supraspinatus tendon.

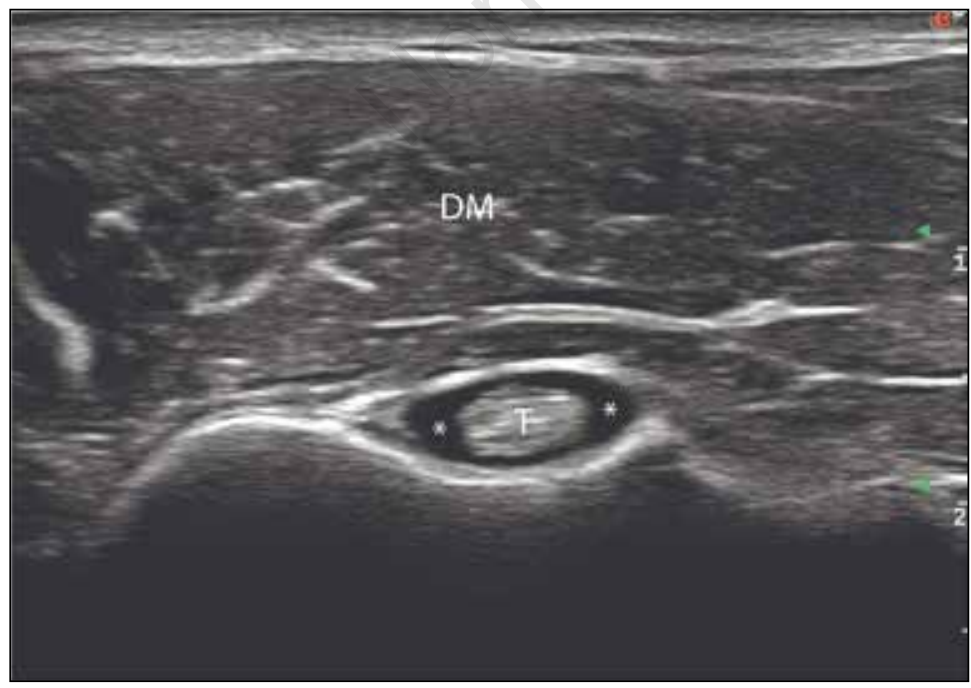

Figure 3 - Exudative tenosynovitis. Trasverse scan of the bicipital groove showing a moderate anechoic widening of the long head tendon sheath (asterisk). T, long head biceps tendon; DM, deltoid muscle. joint synovitis or tenosynovitis of the long head of the biceps, as shown in Figure 3).

The report should be accompanied by a minimum set of six images (supraspinatus, infraspinatus and subcapularis tendons, long head of the biceps tendon, gleno-humeral joint, acromio-clavicular joint) that provide visual evidence of the main structures examined. In case of abnormalities, the number of images must be adequate to the pathologic findings.

\section{DISCUSSION}

MSUS has been increasingly used over the last few years by both radiologists and rheumatologists, as it has proven a reliable diagnostic tool for a variety of muscoloskeletal disorders, including the painful shoulder $(2,4,9,10)$. Both rheumatologists and radiologists tried to define the main diagnostic indications of MSUS $(7,8)$, but, to the best of our knowledge, although there are examples of recommendations for performing shoulder US, no official recommendations are shared by both specialties for reporting US findings. However, it is plausible that the approach of the two specialties to this technique can be different due to their different cultural background. The rheumatologist approach is mainly focused on inflammatory abnormalities of joints (7), while radiologists are usually asked to scan patients with traumatic and degenerative lesions (8). In their guidelines, the radiologist's task force concluded that the main indications for shoulder US are both partial and total tendon injuries, and calcific tendonitis. In the same document, the use of US as a tool to identify inflammatory abnormalities was not taken into consideration.

However, there are several studies, mainly produced by rheumatologists that did not only demonstrate a high sensitivity and specificity, but also a significant consensus between operators when using US to identify inflammatory changes in the shoulder $(11,12)$. In particular, US scanning has proven superior to conventional radiography in demonstrating the presence of bone 
erosions. Also, US can be considered similar to magnetic resonance imaging in detecting synovitis, tenosynovitis and bone erosions $(13,14)$.

These differences in the cultural background of the operators led to several points of discussion during the plenary session. The reporting of tendon injuries was the first discussion topic. Several studies have extensively described the US features of partial and full thickness tears of the rotator cuff $(2,9,15,16)$. On the other hand, US characteristics of the so-called tendinosis (16) are less known and it is difficult to differentiate this condition from partial lesions of tendons (17). During the US scans, radiologists paid particular attention to the description of tendon tears, providing a measurement along two axes and occasionally scoring the tears according to methods used by orthopedic surgeons (18). On the other hand, rheumatologists provided mainly a semi-quantitative description and preferred to describe extensively the abnormalities of the rotator cuff indicating the grade of degeneration. Furthermore rheumatologists paid particular attention to the identification of the timing of the tear (acute, sub-acute or chronic) using also concomitant findings (i.e. effusion, reduction of sub-acromial space). During the discussion, the experts agreed that both approaches are equally important and both quantitative and qualitative evaluations should be reported. Precise measurements, and, when explicitly requested, specific orthopedic scoring systems can be adopted in order to facilitate the assessment of the lesion by the surgeon. On the other hand, the timing of the lesion, the presence of inflammation and the grade of degeneration of the tendons are important when a conservative treatment is preferred.

The correct reporting of intratendinous calcific deposits was another discussion topic. The ESSR task force grouped all kinds of tendon calcifications under the umbrella term of calcific tendonitis and declared that US represents a first-level diagnostic tool for this pathology (8). On the other hand, rheumatologists believe that enthesophytes should be differentiated from calcifica- tions. The former could be the expression of chronic enthesal inflammation, a hallmark of enthesoarthritis (19), while the latter could be a manifestation of a degenerative pathology of the rotator cuff. Therefore, all calcifications identified in the bone which extend to the tendon should be defined as enthesophytes, whereas all calcific deposits located within the tendon but that do not reach the bony cortex should be defined as calcifications. Also, larger oval calcifications within rotator cuff tendons should be regarded as calcific tendonitis, which is yet another pathologic condition $(20,21)$.

The description of discontinuities of the surface of the humeral head was one of the most important comparative points. In particular, the appropriateness of the term erosion was discussed. Radiologists tended to report all irregularities of the bony cortex as erosions. This aspect is quite controversial, because, even if appropriate from a purely semantic point of view, this term evokes the presence of chronic inflammatory arthritis. On the other hand, a study by Schmidt et al showed that erosions findings in the humeral head are not uncommon in healthy subjects (erosions were observed in approximately $20 \%$ of the shoulders) (22). Considering that discontinuities on the humeral bone surface may be found in subjects who are not affected by rheumatic diseases, experts believed that the term erosion should be used only for patients with a known or strongly suggestive history or US findings of chronic arthritis, whereas the term irregularity should be used in the remaining cases.

All experts agreed on the importance of creating a quantitative score with different grades (i.e. absent, mild, moderate, severe) for the assessment of inflammatory changes, such as synovitis, effusion or bursitis. This approach could be useful for the follow-up of patients with either inflammatory or degenerative disease and could help in the assessment of treatment efficacy. Further studies will be necessary in order to develop this score.

On the other hand, regarding the scanning technique, no disagreement emerged between the experts. However, the scan- 
ning technique used by the participants in this study presented some differences compared with the recommended scans described in the literature by both radiologists (6) and rheumatologists (7) (Table I). It was possible to observe that rheumatologists adopted almost completely the scanning technique proposed by radiologists, even though they had not formally reached a consensus before the US scanning session, but they had only relied on their experience. This is in part due to the age of the paper published by Backhaus et al. on behalf of the European League against Rheumatism (EULAR) that dates back to 2001, while the paper published by Jacobson was released ten years later. Furthermore, the paper published by rheumatologists was focused only on the basic scans in order to identify the main rheumatologic disorders of the joints (signs of inflammation) and was not meant to be a guide for advanced US of the shoulder. However, the technology evolution of the equipment, the growing knowledge of sonoanatomy and the spreading of US equipment in rheumatology units have led to an increasing use of US by rheumatologists to diagnose pathologies other than inflammation of the joints, thus bringing the rheumatologic approach to this technique closed to the radiological approach. In our opinion, it could be beneficial for rheumatologists to produce new guidelines for US that are not only focused on inflammatory diseases, but also on degenerative and traumatic disorders. This experience taught us that a shared approach is not impossible and probably the best option is to propose guidelines that can satisfy the needs of both rheumatologists and radiologists, regardless their experience.

This study, the first of its kind as far as we are aware, allowed us to highlight some points of divergence, especially in US reporting, between rheumatologists, experts in MSUS, and radiologists. The small number of patients in the study and the fact that the Delphi method was not used to formalize the final statements are the main weakness of our study.

In conclusion, this article describes an example of direct and positive interaction of two specialties that led to a common and shared approach to reporting US findings of the shoulder. This experiment was appreciated by all participants who believed that rheumatologists and radiologists working side by side could bring MSUS to a new common level by teaching and learning from each other.

Conflicts of interest: the authors declare no conflicts of interest

\section{REFERENCES}

1. Firestein GS, Budd RC, Gabriel SE, McInnes IB, O'Dell JR, eds. Kelley's textbook of rheumatology, 9th ed. Philadelphia, PA: Saunders. 2012.

2. Iagnocco A, Filippucci E, Meenagh G, Delle Sedie A, Riente L, Bombardieri S, et al. Ultrasound imaging for the rheumatologist.I. Ultrasonography of the shoulder. Clin Exp Rheumatology. 2006; 24: 6-11.

3. Salaffi F, Ciapetti A, Carotti M, Gasparini S, Filippucci E, Grassi W. Clinical value of single versus composite provocative clinical tests in the assessment of painful shoulder. J Clin Rheumatol. 2010; 16: 105-8.

4. Naredo E, Aguado P, De Miguel E, Uson J, Mayordomo L, Gijon-Baños J, et al. Painful shoulder: comparision of physical examination and ultasonography findings. Ann Rheum Dis. 2002; 61: 132-6.

5. American College of Radiology (ACR); Society for Pediatric Radiology (SPR); Society of Radiologists in Ultrasound (SRU). AIUM practice guideline for the performance of a musculoskeletal ultrasound examination. J Ultrasound Med. 2012; 31: 1473-88.

6. Jacobson JA. Shoulder US:anatomy, technique and scanning pitfalls. Radiology. 2011; 260: 6-16

7. Backhaus M, Burmester GR, Gerber T, Grassi W, Machold KP, Swen WA. Guidelines for musculoskeletal ultrasound in rheumatology. Ann Rheum Dis. 2001; 60: 641-9.

8. Klauser AS, Tagliafico A, Allen GM, Boutry N, Campbell R, Court-Payen M, et al. Clinical indications for musculoskeletal ultrasound: a Delphi-based consensus paper of the European Society of Musculoskeletal Radiology. Eur Radiol. 2012; 22: 1140-8.

9. Petranova T, Vlad V, Porta F, Radunovic G, Micu MC, Nestorova R, et al Ultrasound of the shoulder. Med Ultrason. 2012; 14: 133-40.

10. Raftery G, Hide G, Kane D. Comparison of musculoskeletal ultrasound practices of a rheumatologist and a radiologist. Rheumatology (Oxford). 2007; 46: 519-22.

11. Naredo E, Möller I, Moragues C, de Agustín 
JJ, Scheel AK, Grassi W, et al. EULAR Working Group for Musculoskeletal Ultrasound. Interobserver reliability in musculoskeletal ultrasonography: results from a "Teach the Teachers" rheumatologist course. Ann Rheum Dis. 2006; 65: 14-9.

12. Bruyn GA, Naredo E, Möller I, Moragues C, Garrido J, de Bock GH, et al Reliability of ultrasonography in detecting shoulder disease in patients with rheumatoid arthritis. Ann Rheum Dis. 2009; 68: 357-61.

13. Hermann KG, Backhaus M, Schneider U, Labs K, Loreck D, Zühlsdorf S, et al. Rheumatoid arthritis of the shoulder joint: Comparison of conventional radiography, ultrasound, and dynamic contrast-enhanced magnetic resonance imaging. Arthritis Rheum. 2003; 48: 3338-49.

14. Amin MF, Ismail FM, El Shereef RR. The role of ultrasonography in early detection and monitoring of shoulder erosions, and disease activity in rheumatoid arthritis patients; comparison with MRI examination. Acad Radiol. 2012; 19: 693-700.

15. Teefey SA, Rubin DA, Middleton WD, Hildebolt CF, Leibold RA, Yamaguchi K. Detection and quantification of rotator cuff tears. Comparison of ultrasonographic, magnetic resonance imaging, and arthroscopic findings in seventy-one consecutive cases. J Bone Joint Surg Am. 2004; 86-A: 708-16.

16. Jacobson JA, Lancaster S, Prasad A, van
Holsbeeck MT, Craig JG, Kolowich P. Fullthickness and partial-thickness supraspinatus tendon tears: value of US signs in diagnosis. Radiology. 2004; 230: 234-42.

17. Beggs I. Shoulder ultrasound. Semin Ultrasound CT MR. 2011; 32: 101-13.

18. Habermeyer P, Krieter C, Tang KL, Lichtenberg S, Magosch P. A new arthroscopic classification of articular-sided supraspinatus footprint lesions: a prospective comparison with Snyder's and Ellman's classification. J Shoulder Elbow Surg. 2008; 17: 909-13.

19. Falsetti P, Acciai C, Lenzi L, Frediani B. Ultrasound of enthesopathy in rheumatic diseases. Mod Rheumatol. 2009; 19: 103-13.

20. Sconfienza LM, Bandirali M, Serafini G, Lacelli F, Aliprandi A, Di Leo G, et al. Rotator cuff calcific tendinitis: does warm saline solution improve the short-term outcome of double-needle US-guided treatment? Radiology. 2012; 262: 560-6.

21. Sconfienza LM, Orlandi D, Fabbro E, Ferrero G, Martini C, Savarino E, et al. Ultrasound assessment of the rotator cuff cable: comparison between young and elderly asymptomatic volunteers and interobserver reproducibility. Ultrasound Med Biol. 2012; 38: 35-41.

22. Schmidt WA, Schmidt H, Schicke B, Gromnica-ihle E. Standard reference values for musculoskeletal ultrasonography. Ann Rheum Dis. 2004; 63: 988-94. 